\title{
Reversal of Startle Gating Deficits in Transgenic Mice Overexpressing Corticotropin-Releasing Factor by Antipsychotic Drugs
}

\author{
Anneloes Dirks*,', Lucianne Groenink', Koen GC Westphal', Jocelien DA Olivier', P Monika Verdouw', Jan \\ van der Gugten', Mark A Geyer ${ }^{2}$ and Berend Olivier ${ }^{1,3}$ \\ 'Department of Psychopharmacology, Utrecht Institute of Pharmaceutical Sciences, Utrecht University, Utrecht, The Netherlands; ${ }^{2}$ Department \\ of Psychiatry, University of California, San Diego, USA; ${ }^{3}$ Department of Psychiatry, Yale University School of Medicine, New Haven, USA
}

\begin{abstract}
Chronically elevated levels of corticotropin-releasing factor (CRF) in transgenic mice overexpressing CRF in the brain (CRF-OE) appear to be associated with alterations commonly associated with major depressive disorder, as well as with sensorimotor gating deficits commonly associated with schizophrenia. In the present study, we tested the hypothesis that antipsychotics may be effective in normalizing prepulse inhibition (PPI) of acoustic startle in CRF-OE mice, which display impaired sensorimotor gating compared to wildtype (WT) mice. The typical antipsychotic haloperidol and atypical antipsychotic risperidone improved PPI in the CRF-OE mice, but were ineffective in WT mice. The atypical antipsychotic clozapine did not influence PPI in CRF-OE mice, but reduced gating in WT mice. This effect of clozapine in the CRF-OE mice may thus be regarded as a relative improvement, consistent with the observed effect of haloperidol and risperidone. As expected, the anxiolytic, nonantipsychotic chlordiazepoxide was devoid of any effect. All four compounds dose-dependently reduced the acoustic startle response irrespective of genotype. These results indicate that antipsychotic drugs are effective in improving startle gating deficits in the CRF-OE mice. Hence, the CRF-OE mouse model may represent an animal model for certain aspects of psychotic depression, and could be a valuable tool for research addressing the impact of chronically elevated levels of CRF on information processing.

Neuropsychopharmacology (2003) 28, 1790-1798, advance online publication, I6 July 2003; doi: I 0. I 038/sj.npp. I 300256
\end{abstract}

Keywords: acoustic startle; prepulse inhibition; CRH; CRF; antipsychotics; sensorimotor gating

\section{INTRODUCTION}

Among the various peptide and neurotransmitter systems that have been implicated in the regulation of stress responses, the corticotropin-releasing factor (CRF, Hauger et al, 2003; also referred to as CRH) system takes a prominent position (Dunn and Berridge, 1990; Owens and Nemeroff, 1991; Koob et al, 1993; Holsboer, 1999; Koob and Heinrichs, 1999). As such, chronically elevated levels of CRF are implicated in stress-related and affective disorders in humans, including major depressive disorder (see Mitchell, 1998; Arborelius et al, 1999; Meyer et al, 2001). Core symptoms of major depression include decreased mood and loss of interest in otherwise pleasurable events and things (DSM-IV). Depression also disturbs fundamental biological

*Correspondence: Dr A Dirks, Department of Psychopharmacology, UIPS, Utrecht University, Sorbonnelaan 16, 3584 CA Utrecht, The Netherlands, Tel: + 3130 2533357, Fax: + 3130 2537387, E-mail: A.Dirks@pharm.uu.nl

Received 18 December 2002; revised 19 May 2003; accepted 21 May 2003

Online publication: 3 June 2003 at http://www.acnp.org/citations/ Npp0603020475/default.pdf processes that regulate autonomic function, neuroendocrine regulation, sleep, appetite, and sexual activity (see Meyer et al, 2001).

To gain more insight into the relationship between chronically elevated levels of CRF and associated neuroendocrine, autonomic, physiological, and behavioral changes, we have developed a transgenic mouse model of life-long CRF overproduction (CRF-OE) (Dirks et al, 2002b; Groenink et al, 2002), under control of the Thy-1 promoter which drives constitutive transgene expression in neurons in postnatal and adult brain (eg Morris and Grosveld, 1989; Vidal et al, 1990; Moechars et al, 1996; Lüthi et al, 1997; Wiessner et al, 1999). Chronic CRF overproduction in the transgenic mice appears to be associated with chronic stress-like alterations, including increased CRF expression and CRF-immunoreactivity in the hypothalamus, increased heart rate and body temperature, decreased heart rate variability, and altered hypothalamus-pituitary-adrenal (HPA) axis activity and regulation, reflected in increased basal plasma corticosterone concentrations, adrenal gland hypertrophy, and nonsuppression of corticosterone secretion in response to dexamethasone (Dirks et al, 2002b; Groenink et al, 2002). 
Apart from these physiological alterations, results of a previous study in CRF-OE mice also indicated that chronic hyperactivity of the CRF system is associated with reductions in startle reactivity and prepulse inhibition (PPI) (Dirks et al, 2002a). The startle reflex is a fast, involuntary contraction of facial and body muscles accompanied by eyelid closure as well as an arrest of ongoing behaviors, evoked by sudden and intense acoustic stimuli (Koch, 1999). PPI is the reduction of the startle response that occurs if the startle stimulus is preceded $30-500 \mathrm{~ms}$ by a distinctive, nonstartling stimulus (prepulse) (Graham, 1975). It is used as an operational measure for early sensorimotor gating (Braff and Geyer, 1990), which is a neural mechanism theorized to maintain mental and behavioral integration by inhibiting irrelevant sensory and cognitive information and motor programs (Dulawa et al, 2000). Impaired PPI has been demonstrated in patients with several neuropsychiatric disorders, most notably schizophrenia (Braff et al, 1978, 1992; for a recent review, see Braff et al, 2001), but not in patients with major depressive disorder without psychosis (W Perry, A Minassian, and D Feifel, personal communication; Ludewig and Ludewig, 2003). Interestingly, acutely administered CRF reduces PPI in rats (Conti et al, 2002) and mice (V Risbrough and M Geyer, personal communication), independent of its effects on startle reactivity. These findings indicate that both acute and chronic elevated levels of CRF have similar disruptive effects on PPI.

A distinct subtype of major depression is psychotic or delusional depression (see Schatzberg and Rothschild, 1992). It is generally referred to as major depression with psychotic features, and is characterized by the presence of delusions or hallucinations (typically auditory) during a major depressive episode (DSM-IV). As such, patients with psychotic depression are preferentially treated with antidepressants, mostly tricyclic antidepressants (TCAs), in combination with antipsychotic drugs (see Wheeler Vega et al, 2000). Recently, it has been suggested that patients with psychotic depression, who have a perturbed HPA axis, also have great difficulties in distinguishing between relevant and irrelevant stimuli (Belanoff et al, 2001). Interestingly, the CRF-OE mice can be characterized by alterations commonly associated with major depression (Dirks et al, 2002b; Groenink et al, 2002), as well as by sensorimotor gating deficits commonly associated with schizophrenia (Dirks et al, 2002a). Therefore, CRF-OE mice might represent an animal model for certain aspects of psychotic depression. To gather further support for this hypothesis, the effects of several antipsychotic drugs on startle reactivity and PPI were assessed in the present study. If indeed the CRF-OE mice can be regarded as representative for psychotic depression, antipsychotic drugs, including haloperidol, clozapine, and risperidone, should reverse the observed startle gating deficits. Nonantipsychotics, such as the anxiolytic chlordiazepoxide, should be devoid of any effect. Furthermore, given its sedative properties, this drug could be used as a control for any antipsychotic-induced sedation.

\section{MATERIALS AND METHODS}

\section{Animals}

CRF-OE mice were generated as described previously (Dirks et al, 2002a, b). Briefly, the CRF transgene was composed of the complete coding sequence of rat CRF cDNA $(0.6 \mathrm{~kb}$ fragment; Thompson et al, 1987), which was inserted into a $8.2 \mathrm{~kb}$ genomic DNA fragment encompassing the murine Thy-1.2 gene, including regulatory regions and polyadenylation signal sequence (Aigner et al, 1995). The Thy-1 regulatory sequences drive constitutive transgene expression in postnatal and adult neurons (Morris and Grosveld, 1989; Vidal et al, 1990; Moechars et al, 1996; Lüthi et al, 1997; Wiessner et al, 1999). Subsequent breeding at the local breeding facilities (Central Laboratory Animal Institute, Utrecht, The Netherlands) consisted of matings between heterozygous transgenic males (C57BL/6J background) and C57BL/6JIco females (obtained from Charles River, The Netherlands).

Male transgenic CRF-OE mice (line 2122, $>7$ th generation) were used in these experiments. Littermate wild-type (WT) mice served as controls. Animals were group-housed at constant room temperature $\left(21 \pm 2^{\circ} \mathrm{C}\right)$ and relative humidity (50-60\%), with EnviroDri ${ }^{\circledR}{ }^{(B M I}$, Helmond, The Netherlands) and a piece of PVC-tubing (diameter $5 \mathrm{~cm}$ ) as cage-enrichment. Standard rodent food pellets (Special Diet Services Ltd., Witham, Essex, UK) and water were freely available. Mice were maintained on a $12 \mathrm{~h}$ light-dark cycle (lights on from 0600 to 1800). All experimental procedures were conducted during the light phase of the cycle. These studies were approved by the ethical committee on animal experiments of the Faculties of Pharmacy, Biology, and Chemistry of Utrecht University, The Netherlands.

\section{Drugs}

Haloperidol (0.3, 1.0, and $3.0 \mathrm{mg} / \mathrm{kg}$; Sigma-RBI, Zwijndrecht, The Netherlands), clozapine (1,3, and $10 \mathrm{mg} / \mathrm{kg}$; Sigma-RBI), and risperidone $(0.25,0.5$, and $1.0 \mathrm{mg} / \mathrm{kg}$; Sigma-RBI) were dissolved in a vehicle containing saline and $0.3 \%$ Tween ${ }^{\circledR} 80$ (Fluka, Buchs, Switzerland). Chlordiazepoxide $(5,10$, and $20 \mathrm{mg} / \mathrm{kg}$, CDP; Pharbita, Zaandam, The Netherlands) was dissolved in saline $(0.9 \% \mathrm{NaCl})$. All drugs were administered intraperitoneally (i.p.) in a volume of $10 \mathrm{ml} / \mathrm{kg}, 30 \mathrm{~min}$ before the start of the test.

\section{Apparatus}

Startle reflexes were measured in four identical startle response systems (SR-LAB, San Diego Instruments, San Diego, CA, USA) consisting of a nonrestrictive Plexiglas cylinder (inner diameter $4 \mathrm{~cm}$, length $13 \mathrm{~cm}$ ) and grid floor, mounted on a Plexiglas platform and placed in a ventilated, sound-attenuated chamber. Cylinder movements were detected and measured by a piezoelectric element mounted under each cylinder. A dynamic calibration system (San Diego Instruments) was used to ensure comparable startle magnitudes across the four devices. Startle stimuli were presented through a high-frequency speaker located $33 \mathrm{~cm}$ above the startle chambers. The background noise was $70 \mathrm{~dB}$. Startle magnitudes were sampled each millisecond (ms) during a period of $65 \mathrm{~ms}$ beginning at the onset of the startle stimulus. A startle response is defined as the peak response during this $65 \mathrm{~ms}$ period. 


\section{Procedure}

A modified procedure of that described by Dulawa and Geyer was adopted (Dulawa and Geyer, 2000; Dulawa et al, 2000).

Matching. Three days prior to the test sessions, mice were exposed to 20 acoustic stimuli ( 100 and $110 \mathrm{~dB}$ noise, $50 \mathrm{~ms}$, interstimulus interval (ISI) $30 \mathrm{~s}$ ). The purpose of this matching procedure was to familiarize the mice to handling, the startle apparatus, and the startle stimulus, and to compose drug groups of mice with equal mean startle magnitudes.

Test sessions. Mice were exposed to five different trial types within a 45 -min session. Startle stimuli $(110 \mathrm{~dB}, 50 \mathrm{~ms})$ were presented alone or were preceded by noise prepulses $(20 \mathrm{~ms})$ of 4,8 , or $16 \mathrm{~dB}$ above background (ie 74,78 , or $86 \mathrm{~dB})$ with a fixed interval $(100 \mathrm{~ms})$ between onsets of the prepulse and startle stimuli. Also, no-stimulus trials were included in which only the background noise was presented to assess spontaneous activity during testing. The test session began with a 5-min acclimatization period followed by three consecutive blocks of test trials. Block one consisted of six consecutive startle stimulus-alone trials, while blocks two and three each contained six startle stimulus-alone trials, five startle + prepulse trials per prepulse intensity, and five no-stimulus trials. Trials were presented in a pseudorandom order within a block. Intertrial intervals ranged from 25 to $35 \mathrm{~s}$.

Experimental design. Each drug was tested in a separate group of animals consisting of CRF-OE and littermate WT mice, age 10-23 weeks (haloperidol: WT $n=15$, CRF-OE $n=14$; clozapine: WT $n=16$, CRF-OE $n=15$; risperidone: WT $n=15$, CRF-OE $n=13$; CDP: WT $n=14$, CRF-OE $n=12$ ). Per drug, mice were tested in a within-subject design, receiving each dose and vehicle once, according to Latin-square treatment protocol. Tests were separated from each other by at least 1 week. Body weight was determined weekly on the day before testing.

\section{Data Analysis}

Startle magnitude is expressed as arbitrary units in all the procedures. Results were evaluated for each drug separately.

Averaged block two and three startle values, which were used for the calculation of PPI, were analyzed by a repeated measures ANOVA with dose as a within-subject factor (four levels) and genotype as a between-subject factor (two levels) to assess startle reactivity.

Percent PPI was calculated as the mean startle magnitude to startle stimulus-alone, minus the mean startle magnitude to startle + prepulse trials, all divided by the mean startle stimulus-alone trials, and multiplied by 100 . Block one startle magnitude values were not used in the calculation of PPI because they reflect the initial rapid habituation of startle and are highly variable (see Dulawa et al, 2000). Results were analyzed by means of repeated measures ANOVA with dose (four levels) and prepulse intensity (three levels) as within-subject factors and genotype (two levels) as a between-subject factor. In the case of significant dose $\times$ prepulse intensity interaction, data were reanalyzed by means of repeated measures ANOVAs with dose as a within-subject factor and genotype as a between-subject factor for each prepulse intensity separately. In the case of significant dose $\times$ genotype interaction, data were reanalyzed by means of repeated measures ANOVAs with dose and prepulse intensity as within-subject factors for each genotype separately. Post hoc tests consisted of independent $t$-tests with Bonferroni correction of $\alpha$.

Body weight across experiments was analyzed by means of repeated measures ANOVA with week (four levels) as a within-subject factor and genotype (two levels) as a between-subject factor.

If appropriate, the Greenhouse-Geisser correction factor

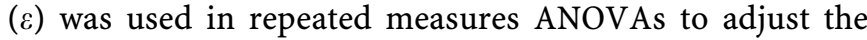
degrees of freedom (Vasey and Thayer, 1987). The level of significance was set at $p<0.05$.

\section{RESULTS}

\section{Acoustic Startle}

Figure 1 shows the effects of haloperidol $(0,0.3,1.0$, and $3.0 \mathrm{mg} / \mathrm{kg})$, clozapine $(0,1,3$, and $10 \mathrm{mg} / \mathrm{kg})$, risperidone $(0$, $0.25,0.5$, and $1.0 \mathrm{mg} / \mathrm{kg})$, and chlordiazepoxide $(0,5,10$, and $20 \mathrm{mg} / \mathrm{kg}$ ) on the averaged startle response in blocks two and three. Within each drug cohort, startle magnitudes of vehicle-treated WT and CRF-OE mice were not significantly different (haloperidol $\mathrm{F}(1,27)=0.04, \quad \mathrm{NS}$; clozapine $\mathrm{F}(1,29)=1.11$, NS; risperidone $\mathrm{F}(1,26)=0.21$, NS; chlordiazepoxide $\mathrm{F}(1,24)=0.66$, NS).

All four compounds decreased startle reactivity irrespective of genotype (haloperidol: dose $\mathrm{F}(3,81)=4.78, p<0.05$, $\varepsilon=0.63$, genotype $\mathrm{F}(1,27)=0.12$, NS, dose $\times$ genotype $\mathrm{F}(3,81)=0.44, \quad \mathrm{NS}, \quad \varepsilon=0.63$; $\quad$ clozapine: dose $\mathrm{F}(3,87)=37.98, p<0.001, \varepsilon=0.67$, genotype $\mathrm{F}(1,29)=1.68$, NS, dose $\times$ genotype $\mathrm{F}(3,87)=0.52$, NS, $\varepsilon=0.67$; risperidone: dose $\mathrm{F}(3,78)=44.49, \quad p<0.001 ; \quad$ genotype $\mathrm{F}(1,26)=0.32$, NS, dose $\times$ genotype $\mathrm{F}(3,78)=0.13$, NS; chlordiazepoxide: dose $\mathrm{F}(3,72)=3.67, p<0.05, \varepsilon=0.77$, genotype $\mathrm{F}(1,24)=2.09, \mathrm{NS}$, dose $\times$ genotype $\mathrm{F}(3,72)=2.04$, NS, $\varepsilon=0.77$ ).

\section{Prepulse Inhibition}

Figure 2 shows the effects of haloperidol $(0,0.3,1.0$, and $3.0 \mathrm{mg} / \mathrm{kg})$, clozapine $(0,1,3$, and $10 \mathrm{mg} / \mathrm{kg})$, risperidone $(0$, $0.25,0.5$, and $1.0 \mathrm{mg} / \mathrm{kg})$, and chlordiazepoxide $(0,5,10$, and $20 \mathrm{mg} / \mathrm{kg}$ ) on percent PPI scores. Within each drug cohort, a significant main effect for genotype was observed in vehicletreated animals (haloperidol $\mathrm{F}(1,27)=8.03, p<0.01$; clozapine $\mathrm{F}(1,29)=18.73, p<0.001$; risperidone $\mathrm{F}(1,26)=7.58$, $p<0.05 ; \quad$ chlordiazepoxide $\mathrm{F}(1,24)=12.61, \quad p<0.005)$. Furthermore, in the haloperidol and risperidone cohorts, there was also a significant genotype $\times$ prepulse intensity interaction (haloperidol $\mathrm{F}(2,54)=5.89, p<0.01$; clozapine $\mathrm{F}(2,58)=0.70$, NS, $\varepsilon=0.81$; risperidone $\mathrm{F}(2,52)=8.87$, $p<0.001$; chlordiazepoxide $\mathrm{F}(2,48)=0.90$, NS, $\varepsilon=0.68$ ).

The percent PPI was monotonically related to the intensity of the prepulse in all cohorts (Figure 2; haloperidol: $\mathrm{F}(2,54)=281.31, p<0.001$; clozapine: $\mathrm{F}(2,58)=140.28$, $p<0.001$; risperidone: $\mathrm{F}(2,52)=255.93, p<0.001, \varepsilon=0.64$; 

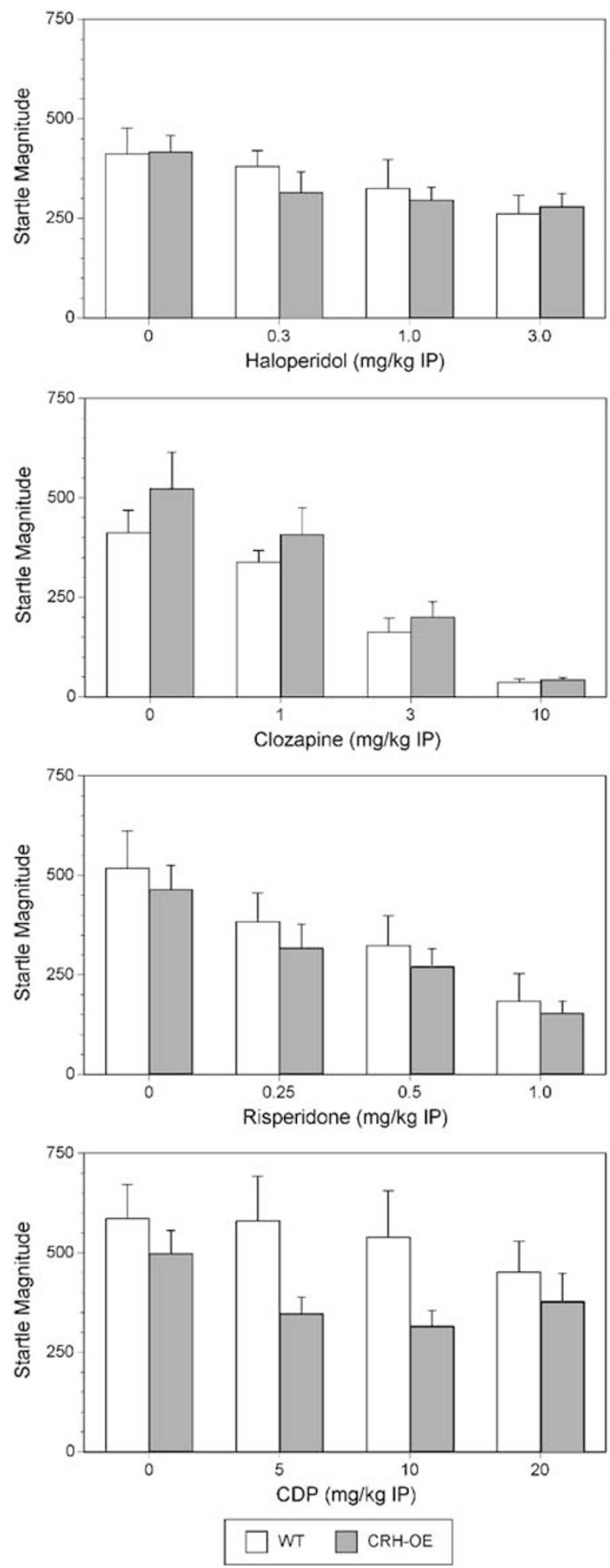

Figure I Effects of haloperidol, clozapine, risperidone, and chlordiazepoxide on the acoustic startle response in WT (white bars) and CRF-OE (gray bars) mice. Haloperidol: WT $n=15, \mathrm{CRF}-\mathrm{OE} n=14$; clozapine: WT $n=16, C R F-O E n=15$, risperidone: $W T n=15, C R F-O E n=13$; CDP: $\mathrm{WT} n=14, \mathrm{CRF}-\mathrm{OE} n=12$

chlordiazepoxide: $\mathrm{F}(2,48)=305.96, \quad p<0.001, \quad \varepsilon=0.75)$. Furthermore, CRF-OE mice displayed impaired levels of PPI as a function of the prepulse intensity, reflected in (nearly) significant main effects of genotype (haloperidol:
$\mathrm{F}(1,27)=13.60, p<0.005$; clozapine: $\mathrm{F}(1,29)=5.34, p<0.05$; risperidone: $\mathrm{F}(1,26)=3.25, \quad p=0.083$; chlordiazepoxide: $\mathrm{F}(1,24)=20.37, p<0.001)$, and significant prepulse intensity $\times$ genotype interactions (haloperidol: $\mathrm{F}(2,54)=14.21$, $p<0.001$; clozapine: $\mathrm{F}(2,58)=9.75, p<0.001$; risperidone: $\mathrm{F}(2,52)=7.84, \quad p<0.01, \quad \varepsilon=0.64 ; \quad$ chlordiazepoxide: $\mathrm{F}(2,48)=4.24, p<0.05, \varepsilon=0.75)$.

As shown in Figure 2, haloperidol increased PPI dosedependently $(\mathrm{F}(3,81)=5.64, p<0.005)$, regardless of genotype (dose $\times$ genotype: $F(3,81)=2.16$, NS), but dependent on prepulse intensity (dose $\times$ prepulse intensity: $\mathrm{F}(6,162)=2.82, p<0.05, \varepsilon=0.72$; dose $\times$ prepulse intensity $\times$ genotype: $\mathrm{F}(6,162)=1.40$, NS, $\varepsilon=0.72)$. Lower order ANOVAs on each prepulse intensity separately revealed a significant dose $\times$ genotype interaction only at the 8 - $d B$ prepulse intensity. Post hoc independent $t$-tests revealed that the differences in PPI between CRF-OE and WT mice were no longer evident after 1.0 and $3.0 \mathrm{mg} / \mathrm{kg}$ haloperidol.

Clozapine affected PPI dose-dependently and genotypedependently (Figure 2; dose: $\mathrm{F}(3,87)=8.12, \quad p<0.001$; dose $\times$ genotype: $\mathrm{F}(3,87)=11.74, p<0.001$; dose $\times$ prepulse intensity: $\quad \mathrm{F}(6,174)=5.73, \quad p<0.001, \quad \varepsilon=0.65 ; \quad$ dose $\times$ prepulse intensity $\times$ genotype: $F(6,174)=1.34, \quad N S$, $\varepsilon=0.65)$. When analyzing each prepulse intensity separately, as permitted by the significant dose $\times$ prepulse intensity interaction, repeated measures ANOVAs revealed significant dose $\times$ genotype interactions at all prepulse intensities. Accompanying post hoc independent $t$-tests revealed that the differences in PPI between CRF-OE and WT mice were no longer evident after 3 and $10 \mathrm{mg} / \mathrm{kg}$ clozapine. When analyzing each genotype separately, as allowed by the significant dose $\times$ genotype interaction, analyses reveal that the $10-\mathrm{mg} / \mathrm{kg}$ clozapine dose induced a significant reduction of PPI in the WT mice at the $8-\mathrm{dB}$ prepulse intensity, while 3 and $10 \mathrm{mg} / \mathrm{kg}$ did so at $16 \mathrm{~dB}$. In CRF-OE mice, clozapine did not affect PPI differentially at different prepulse intensities, reflected by a nonsignificant dose $\times$ prepulse interaction.

After risperidone treatment, PPI was also changed dosedependently and genotype-dependently (Figure 2; dose: $\mathrm{F}(3,78)=1.50, \mathrm{NS}$; dose $\times$ genotype: $\mathrm{F}(3,78)=4.31, p<0.01$; dose $\times$ prepulse intensity: $\mathrm{F}(6,156)=3.46, p<0.005$; dose $\times$ prepulse intensity $\times$ genotype: $\quad \mathrm{F}(6,156)=2.08$, $p=0.058)$. When analyzing each prepulse intensity separately, as permitted by the significant dose $\times$ prepulse intensity interaction, repeated measures ANOVAs revealed significant main effects of genotype and significant dose $\times$ genotype interactions at prepulse intensities of 4 and $8 \mathrm{~dB}$ with CRF-OE mice showing significantly less PPI than WT mice after vehicle treatment. This difference between genotypes disappeared after risperidone treatment. When analyzing the genotypes separately, risperidone improved PPI in the CRF-OE mice, particularly at $0.25 \mathrm{mg} / \mathrm{kg}$ after $4 \mathrm{~dB}$ prepulses and at $1.0 \mathrm{mg} / \mathrm{kg}$ after $8 \mathrm{~dB}$ prepulses. In WT mice, risperidone did not affect PPI differentially at different prepulse intensities, reflected by a nonsignificant dose $\times$ prepulse interaction.

As expected, chlordiazepoxide had no effect on PPI (Figure 2; dose: $\mathrm{F}(3,72)=0.41$, NS; dose $\times$ genotype: $\mathrm{F}(3,72)=0.63, \quad \mathrm{NS} ; \quad$ dose $\times$ prepulse intensity: $\mathrm{F}(6,144)=1.64$, NS, $\varepsilon=0.48$; dose $\times$ prepulse intensity $\times$ genotype: $\mathrm{F}(6,144)=0.87$, NS, $\varepsilon=0.48)$. 

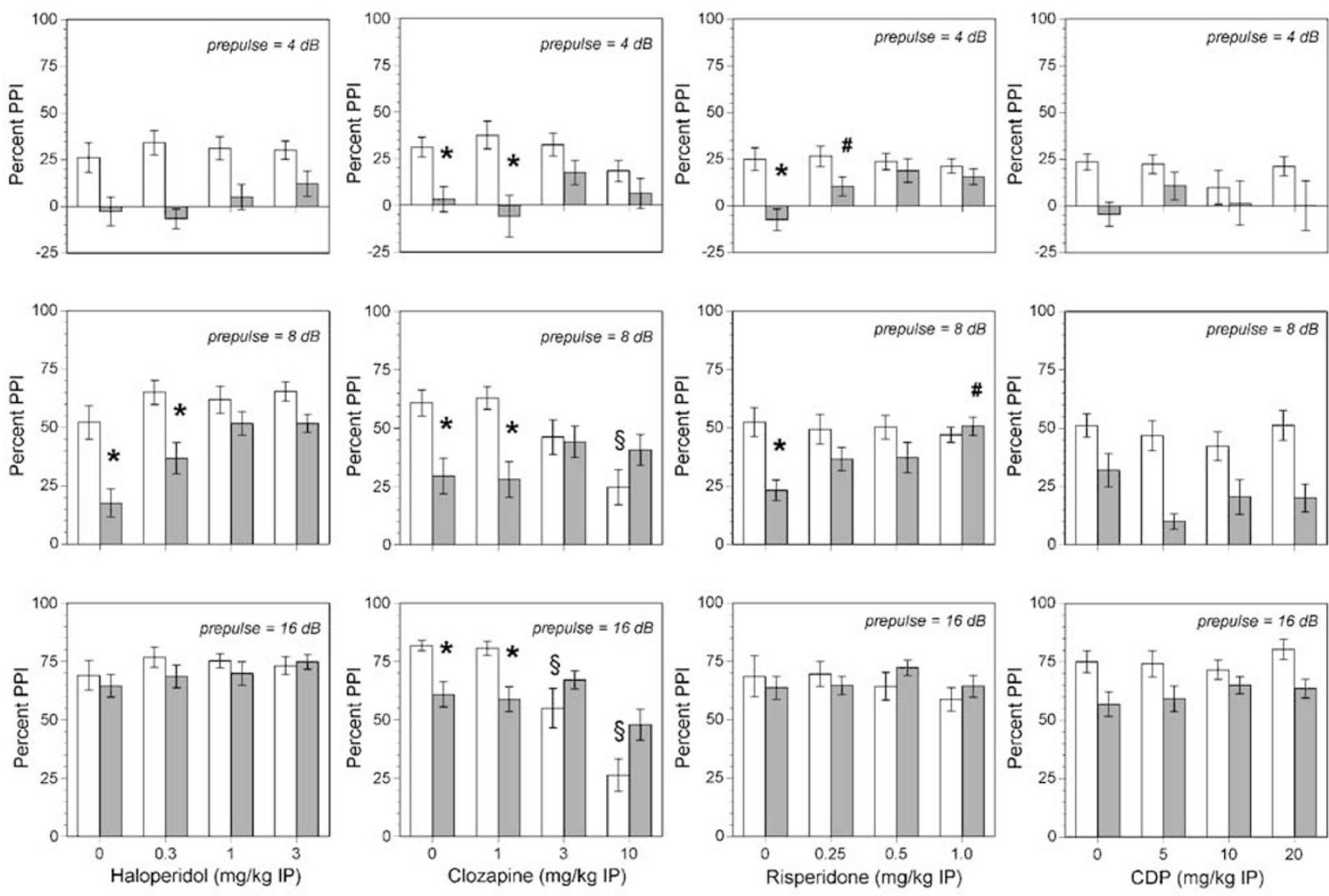

WT $\square \mathrm{CRH}-\mathrm{OE}$

Figure 2 Effects of haloperidol, clozapine, risperidone, and chlordiazepoxide on prepulse inhibition of the acoustic startle response in WT (white bars) and CRF-OE (gray bars) mice. The main effect of genotype was significant in each of the four cohorts of mice tested. Haloperidol: WT $n=15$, CRF-OE $n=14$; clozapine: WT $n=16$, CRF-OE $n=15$; risperidone: WT $n=15$, CRF-OE $n=13$; CDP: WT $n=14$, CRF-OE $n=12$. * $p<0.05$ vs same-dose-treated WT mice, ${ }^{\circledR} p<0.05$ vs vehicle-treated WT mice, ${ }^{\#} p<0.05$ vs vehicle-treated CRF-OE mice.

\section{Body Weight}

At the start of the experiments, CRF-OE mice had significantly lower body weights than WT (WT: $n=60$, $29.0 \pm 0.4$ g; CRF-OE: $n=54,25.5 \pm 0.5 \mathrm{~g} ;=5.97, \mathrm{df}=112$, $p<0.001)$. These differences in body weight between genotypes remained present throughout all procedures (week: $\quad \mathrm{F}(3,336)=74.06, \quad p<0.001 ; \quad$ genotype: $\mathrm{F}(1,112)=32.18, \quad \quad p<0.001 ; \quad$ week $\times$ genotype: $\mathrm{F}(3,336)=1.83$, NS; $\varepsilon=0.73)$. The same holds true for each drug cohort separately.

\section{DISCUSSION}

The main objective of this study was to test the hypothesis that antipsychotics may be effective in improving PPI in the CRF-OE mice, which displayed impaired sensorimotor gating when compared to WT mice in each of the four cohorts examined. Indeed, both the typical antipsychotic haloperidol and atypical antipsychotic risperidone improved PPI in the CRF-OE mice, while they were ineffective in WT mice. The atypical antipsychotic clozapine did not have an effect on PPI in the CRF-OE mice, although it reduced gating in WT mice. This effect of clozapine in the CRF-OE mice may thus be regarded as a relative improve- ment, consistent with the observed effect of haloperidol and risperidone. As expected, the nonantipsychotic and anxiolytic chlordiazepoxide were devoid of any effect. These results indicate that antipsychotic drugs are effective in reversing the startle gating deficits in the CRF-OE mice.

In the four independent cohorts of mice tested here, we replicated previous results showing decreased startle plasticity as evidenced by impaired PPI in the CRF-OE mice, although the concomitant decrease in startle reactivity observed previously was not confirmed in the present experiments (Dirks et al, 2002a), possibly due to the confounding effects of injection stress. As CRF-OE mice overproduce CRF throughout postnatal development, numerous neurochemical and developmental changes may have occurred to compensate for the increased levels of this neuropeptide. Thus, it cannot be ruled out that the observed phenotype is not the direct consequence of chronically CRF excess, but rather the result of compensatory adaptations in other neurotransmitter systems involved in startle reactivity and startle plasticity. Nevertheless, it was recently reported that acutely administered CRF reduces PPI in two strains of rats, independent of its effects on acoustic startle amplitude (Conti et al, 2002). This observation, coupled with preliminary observations of similar effects of CRF on PPI in two strains of mice (V Risbrough and M Geyer, personal 
communication), indicates that both acute administrations and chronic overexpression of $\mathrm{CRF}$ have similar disruptive effects on PPI. Another possible concern is that the lower body weight in CRF-OE mice might have contributed to the observed difference in startle reactivity. This possibility appears to be unlikely because there was no significant correlation between acoustic startle magnitude and body weight (data not shown). Another potential concern when testing PPI in mice involves hearing deficits. C57BL/6 mice hear normally as young adults (1-2 months of age), but exhibit high-frequency hearing loss $(>20 \mathrm{kHz})$ by $5-6$ months, accompanied by increased behavioral salience of low and middle frequencies (eg Parham and Willott, 1988; Willott et al, 1994; Carlson and Willott, 1996). In this case, however, the WT and CRF-OE mice on a C57BL/6J background were well below the critical age, and we used noise with a broad sound frequency spectrum for both prepulse and startle stimuli, thus avoiding stimuli with just one frequency. Furthermore, if the reduced PPI in the CRF-OE mice were due to hearing deficits, such hearing deficits would have to be reversible by acute administrations of antipsychotic drugs, as seen in the present studies. Hence, we think that it is highly unlikely that high-frequency hearing loss contributed to the observed effects.

In this study, the effects of haloperidol (typical antipsychotic, dopamine $\mathrm{D}_{2}$ receptor antagonist), clozapine (atypical antipsychotic, $\mathrm{D}_{1} / \mathrm{D}_{2} / \mathrm{D}_{3} / \mathrm{D}_{4} / 5-\mathrm{HT}_{2} / \alpha_{1} /$ muscarinic receptor antagonist), and risperidone (atypical antipsychotic, $\mathrm{D}_{2} / 5-\mathrm{HT}_{2} / \alpha_{1} / \alpha_{2}$ receptor antagonist) on startle reactivity and PPI were investigated in CRF-OE and WT mice. The three compounds dose-dependently reduced the acoustic startle response irrespective of genotype. These findings correspond well with reported effects of these antipsychotics in mice. Although it has been reported that haloperidol increases startle reactivity over a wide dose range in mice (McCaughran Jr et al, 1997), others report a decrease in startle response after haloperidol treatment in mice, as is commonly seen in rats (Mansbach et al, 1988; Ouagazzal et al, 2001). Also, clozapine decreases startle response in mice of different background strains, including C57BL/6J (Olivier et al, 2001; Ouagazzal et al, 2001). In C57BL/6J mice, risperidone had either no effect on startle amplitude (McCaughran Jr et al, 1997; Olivier et al, 2001), or reduced startle reactivity (Ouagazzal et al, 2001). In our study, at the two highest doses of clozapine, mice showed clear signs of sedation, which is a known side effect of this drug (see Miller, 2000) that could explain the marked reduction observed in startle reactivity. In concordance, the benzodiazepine chlordiazepoxide reduced startle reactivity most likely due to its sedative properties, although this effect was not robust. Furthermore, catalepsy, which is a good predictor of extrapyramidal side effects of antipsychotic drugs (see Hoffman and Donovan, 1995), was observed in most but not all mice of both genotypes after 0.5 and $1.0 \mathrm{mg} / \mathrm{kg}$ risperidone. Unexpectedly, although haloperidol reduced startle reactivity as did risperidone, it did not induce obvious catalepsy. Risperidone- and haloperidolinduced catalepsy have often been described in rodents (eg Kanes et al, 1993; Hoffman and Donovan, 1995; Rigdon et al, 1996; Wadenberg et al, 2001). For risperidone, the $\mathrm{ED}_{50}$ value was $1.8 \mathrm{mg} / \mathrm{kg} \mathrm{PO}$ (in CD-1 mice) and for haloperidol it was $3.8 \mathrm{mg} / \mathrm{kg}$ PO (in C57BL/6J mice) (see Kanes et al, 1993; Rigdon et al, 1996). Hence, the absence of haloperidol-induced catalepsy in the present study could be related to the dose used (ie ranging from 0.3 to $3.0 \mathrm{mg} / \mathrm{kg}$ i.p.).

Both haloperidol and risperidone reversed the disrupted PPI in the CRF-OE mice, while being ineffective in WT mice. These results in the WT mice do not correspond with previous results. In $\mathrm{WT} \mathrm{C} 57 \mathrm{BL} / 6 \mathrm{~J}$ mice, haloperidol has been suggested to facilitate PPI (McCaughran Jr et al, 1997), although in another study haloperidol was only effective at the highest prepulse intensity tested (Ouagazzal et al, 2001). Also, the atypical antipsychotic risperidone appears to produce dose-dependent improvements in PPI (McCaughran Jr et al, 1997; Ouagazzal et al, 2001), although this finding is not unequivocal (Olivier et al, 2001). Differences between our results in WT mice and those reported in the literature may be due to substrain differences in drug responses and/or differences in stimulus parameters, PPI parameters, and startle measurement methods. The results in the CRF-OE mice, however, are in agreement with previously reported effects of these compounds on PPI deficits in rats. As recently reviewed by Geyer et al (2001), pharmacological manipulations with dopamine receptor agonists, $5-\mathrm{HT}_{2}$ receptor agonists, or NMDA receptor antagonists, or developmental manipulations including isolation rearing, produce robust deficits in PPI in rats, which can be reversed by haloperidol, clozapine, and/or risperidone, depending upon the particular PPI disruption model used. In rats, these compounds generally have minimal effects on PPI by themselves, although some increases or decreases have been reported that appear to depend on strain, startle parameters, and doses used (see Geyer et al, 2001).

Unexpectedly, clozapine induced a severe reduction of PPI in WT mice, although it was devoid of any effect in the CRF-OE mice. When analyzing absolute startle values, instead of percentage PPI scores, after 3 and $10 \mathrm{mg} / \mathrm{kg}$ clozapine, as allowed by a significant dose $\times$ prepulse intensity interaction in an overall repeated measures ANOVA on absolute startle values (statistics not shown), there is still a significant effect of prepulse intensity irrespective of genotype (statistics not shown), indicating that startle magnitudes are reduced even further, despite startle values of around 50 in the stimulus-alone trials. It is therefore unlikely that the reduction in percent PPI as observed in the WT mice, is derived from a floor effect. Nonetheless, given the strongly reduced startle reactivity after clozapine treatment, the PPI results are difficult to interpret in any definitive way. Clozapine usually potentiates PPI in mice in the same dose range used in this study (McCaughran Jr et al, 1997; Olivier et al, 2001; Ouagazzal et al, 2001). In these studies, saline-treated mice of the C57BL/6J strain showed low levels of PPI, ranging from approximately 10 to $40 \%$ (McCaughran Jr et al, 1997; Olivier et al, 2001; Ouagazzal et al, 2001), in concordance with previously reported PPI values for this strain (Paylor and Crawley, 1997). However, in the present and previous study in CRF-OE mice (Dirks et al, 2002a), the levels of PPI are substantially higher in the WT C57BL6/J mice dependent on the intensity of the prepulse. These findings suggest that, at least in C57BL/6J mice, the effects of clozapine may depend 
on the initial levels of PPI. Thus, the differences in basal PPI levels between present and previous studies may account for the unusual PPI-impairing effect of clozapine observed in the WT C57BL/6J mice. In the CRF-OE mice, clozapine did not induce an impairment of PPI as seen in the WT mice. Given the absence of such clozapine-induced reduction of PPI in the CRF-OE mice, and given that haloperidol and risperidone improved PPI in CRF-OE mice while being ineffective in WT mice, this effect of clozapine in the CRF$\mathrm{OE}$ mice may tentatively be regarded as a relative improvement, and is therefore consistent with the observed effects of haloperidol and risperidone.

We and others have shown repeatedly that sensorimotor gating processes are not generally linked to startle reactivity per se and are independent of the magnitude of the startle response in mice (eg Paylor and Crawley, 1997; Ouagazzal et al, 2001; Dirks et al, 2001). The present results are in concordance with these reports. For example, risperidone improved PPI only in CRF-OE mice, while it decreased startle reactivity in both genotypes. It should be noted that it does not always follow that effects of startle can never affect PPI scores, and should not be considered as a potential confound of PPI results (see Swerdlow et al, 2000).

The neurodevelopmental hypothesis of schizophrenia suggests that an abnormal development of the brain connectivity resulting from a genetic predisposition in combination with pre- or early postnatal environmental factors, could be one of the mechanisms implicated in the genesis of schizophrenia (Ellenbroek and Cools, 1998; Lipska and Weinberger, 2000). In the CRF-OE mice, the onset of transgene expression, under control of the Thy-1 promoter, occurs shortly after birth reaching maximum levels by postnatal day 14, which are retained throughout adult life (Lüthi et al, 1997). Hence, the early postnatal onset of CRF overexpression and associated consequences for neuroendocrine, neurochemical, autonomic, and developmental processes, could be regarded comparable to other developmental manipulations such as maternal deprivation, neonatal hippocampus lesioning, and isolation rearing. All these manipulations result in sensorimotor gating deficits in adult life (Geyer et al, 1993; Ellenbroek et al, 1998; Lipska and Weinberger, 2000), which can be reversed by both typical and atypical antipsychotic drugs (Ellenbroek et al, 1998; Geyer et al, 2001; Le Pen and Moreau, 2002). The results of the present study suggest that the CRF-OE mouse model might be an additional animal model to study the long-term effects of early postnatal homeostatic disturbances on sensorimotor gating.

In conclusion, the present study shows that antipsychotic drugs (haloperidol, risperidone, and clozapine) are effective in reversing startle gating deficits in the CRF-OE mice, independent of their effects on startle reactivity per se. Impaired PPI has been demonstrated in patients with several neuropsychiatric disorders, most notably schizophrenia (Braff et al, 1978, 1992); for a recent review, see Braff et al, 2001), but not in patients with major depressive disorder without psychosis (W Perry, A Minassian, and D Feifel, personal communication; Ludewig and Ludewig, 2003). However, the effects of antipsychotic treatment on PPI in schizophrenic patients are not consistent, with some studies showing normalization of PPI and others not (see
Braff et al, 2001; Kumari et al, 2002; Kumari and Sharma, 2002). Psychotic depression, a distinct subtype of major depression, shares many features with schizophrenia, with psychosis being the most prominent (see Schatzberg and Rothschild, 1992). The disorder is generally referred to as major depression with psychotic features, and is characterized by the presence of delusions or auditory hallucinations, and by, among others, excessive HPA axis activity, marked nonsuppression of cortisol secretion after dexamethasone, cognitive and neurophysiological changes, a good response to treatment with an antidepressant plus an antipsychotic, and a joint disturbance of dopaminergic and serotonergic systems (see Anton, 1987; Schatzberg and Rothschild, 1992; Schatzberg et al, 2000; Wheeler Vega et al, 2000; Belanoff et al, 2001). However, to our knowledge, published data on PPI values in patients with psychotic depression are not available. Interestingly, the CRF-OE mice can be characterized by alterations commonly associated with major depression (Dirks et al, 2002b; Groenink et al, 2002) as well as sensorimotor gating deficits commonly associated with schizophrenia or psychosis (Dirks et al, 2002a), which can be reversed by antipsychotic drugs as shown in the present study. Therefore, the CRF-OE mouse model may represent an animal model for certain aspects of psychotic depression, and could be a valuable tool for research addressing the impact of chronically elevated levels of CRF on information processing.

\section{ACKNOWLEDGEMENTS}

We thank Mr Wim van der Wal for screening tail DNA, and Mr Filip van den Bergh, MSc, for his help with the figures.

\section{REFERENCES}

Aigner L, Arber S, Kapfhammer JP, Laux T, Schneider C, Botteri F et al (1995). Overexpression of the neural growth-associated protein GAP-43 induces nerve sprouting in the adult nervous system of transgenic mice. Cell 83: 269-278.

Anton RF (1987). Urinary free cortisol in psychotic depression. Biol Psychiatry 22: 24-34.

Arborelius L, Owens MJ, Plotsky PM, Nemeroff CB (1999). The role of corticotropin-releasing factor in depression and anxiety disorders. J Endocrinol 160: 1-12.

Belanoff JK, Kalehzan M, Sund B, Fleming Ficek SK, Schatzberg AF (2001). Cortisol activity and cognitive changes in psychotic major depression. Am J Psychiatry 158: 1612-1616.

Braff DL, Geyer MA (1990). Sensorimotor gating and schizophrenia. Human and animal model studies. Arch Gen Psychiatry 47: 181-188.

Braff DL, Geyer MA, Swerdlow NR (2001). Human studies of prepulse inhibition of startle: normal subjects, patient groups, and pharmacological studies. Psychopharmacology (Berl) 156: 234-258.

Braff DL, Grillon C, Geyer MA (1992). Gating and habituation of the startle reflex in schizophrenic patients. Arch Gen Psychiatry 49: 206-215.

Braff DL, Stone C, Callaway E, Geyer MA, Glick I, Bali L (1978). Prestimulus effects on human startle reflex in normals and schizophrenics. Psychophysiology 15: 339-343.

Carlson S, Willott JF (1996). The behavioral salience of tones as indicated by prepulse inhibition of the startle response: relationship to hearing loss and central neural plasticity in C57BL/6J mice. Hear Res 99: 168-175. 
Conti LH, Murry JD, Ruiz MA, Printz MP (2002). Effects of corticotropin-releasing factor on prepulse inhibition of the acoustic startle response in two rat strains. Psychopharmacology 161: 296-303.

Dirks A, Groenink L, Bouwknecht JA, Hijzen TH, van der Gugten J, Ronken E et al (2002b). Overexpression of corticotropinreleasing hormone in transgenic mice and chronic stress-like autonomic and physiological alterations. Eur J Neurosci 16: $1751-1760$.

Dirks A, Groenink L, lutje Schipholt M, van der Gugten J, Hijzen TH, Geyer MA et al (2002a). Reduced startle reactivity and plasticity in transgenic mice overexpressing corticotropinreleasing hormone. Biol Psychiatry 51: 583-590.

Dirks A, Pattij T, Bouwknecht JA, Westphal TT, Hijzen TH, Groenink L et al (2001). 5- $\mathrm{HT}_{1 \mathrm{~B}}$ receptor knockout, but not 5$\mathrm{HT}_{1 \mathrm{~A}}$ receptor knockout mice, show reduced startle reactivity and footshock-induced sensitization, as measured with the acoustic startle response. Behav Brain Res 118: 169-178.

Dulawa SC, Geyer MA (2000). Effects of strain and serotonergic agents on prepulse inhibition and habituation in mice. Neuropharmacology 39: 2170-2179.

Dulawa SC, Scearce-Levie K, Hen R, Geyer MA (2000). Serotonin releasers increase prepulse inhibition in serotonin 1B knockout mice. Psychopharmacology (Berl) 149: 306-312.

Dunn AJ, Berridge CW (1990). Physiological and behavioral responses to corticotropin-releasing factor administration: is CRF a mediator of anxiety or stress responses? Brain Res Brain Res Rev 15: 71-100.

Ellenbroek BA, Cools AR (1998). The neurodevelopmental hypothesis of schizophrenia: clinical evidence and animal models. Neurosci Res Commun 22: 127-136.

Ellenbroek BA, van den Kroonenberg PT, Cools AR (1998). The effects of an early stressful life event on sensorimotor gating in adult rats. Schizophr Res 30: 251-260.

Geyer MA, Krebs-Thomson K, Braff DL, Swerdlow NR (2001). Pharmacological studies of prepulse inhibition models of sensorimotor gating deficits in schizophrenia: a decade in review. Psychopharmacology (Berl) 156: 117-154.

Geyer MA, Wilkinson LS, Humby T, Robbins TW (1993). Isolation rearing of rats produces a deficit in prepulse inhibition of acoustic startle similar to that in schizophrenia. Biol Psychiatry 34: $361-372$.

Graham FK (1975). The more or less startling effects of weak prestimulation. Psychophysiology 12: 238-248.

Groenink L, Dirks A, Verdouw PM, lutje Schipholt M, Veening JG, van der Gugten J et al (2002). HPA-axis dysregulation in mice overexpressing corticotropin-releasing-hormone. Biol Psychiatry 51: $875-881$.

Hauger RL, Grigoriadis DE, Dallman MF, Plotsky PM, Vale WW, Dautzenberg FM (2003). International union of pharmacology. XXXVI. Current status of the nomenclature for receptors for corticotropin-releasing factor and their ligands. Pharmacol Rev 55: 21-26.

Hoffman DC, Donovan H (1995). Catalepsy as a rodent model for detecting antipsychotic drugs with extrapyramidal side effect liability. Psychopharmacology (Berl) 120: 128-133.

Holsboer F (1999). The rationale for corticotropin-releasing hormone receptor (CRH-R) antagonists to treat depression and anxiety. J Psychiatr Res 33: 181-214.

Kanes SJ, Hitzemann BA, Hitzemann RJ (1993). On the relationship between D2 receptor density and neuroleptic-induced catalepsy among eight inbred strains of mice. J Pharmacol Exp Ther 267: 538-547.

Koch M (1999). The neurobiology of startle. Prog Neurobiol 59: 107-128.

Koob GF, Heinrichs SC (1999). A role for corticotropin releasing factor and urocortin in behavioral responses to stressors. Brain Res 848: 141-152.
Koob GF, Heinrichs SC, Merlo Pich E, Menzaghi F, Baldwin HA, Miczek KA et al (1993). The role of corticotropin-releasing factor in behavioural responses to stress. Ciba Found Symp 172: 277-295.

Kumari V, Sharma T (2002). Effects of typical and atypical antipsychotics on prepulse inhibition in schizophrenia: a critical evaluation of current evidence and directions for future research. Psychopharmacology 162: 97-101.

Kumari V, Soni W, Sharma T (2002). Prepulse inhibition of the startle response in risperidone-treated patients: comparison with typical antipsychotics. Schizophr Res 55: 139-146.

Le Pen G, Moreau JL (2002). Disruption of prepulse inhibition of startle reflex in a neurodevelopmental model of schizophrenia. Reversal by clozapine, olanzapine and risperidone but not by haloperidol. Neuropsychopharmacology 27: 1-11.

Lipska BK, Weinberger DR (2000). To model a psychiatric disorder in animals: schizophrenia as a reality test. Neuropsychopharmacology 23: 223-239.

Ludewig S, Ludewig K (2003). No prepulse inhibition deficits in patients with unipolar depression. Depress Anxiety 17: 224-225.

Lüthi A, van der Putten H, Botteri FM, Mansuy IM, Meins M, Frey $\mathrm{U}$ et al (1997). Endogenous serine protease inhibitor modulates epileptic activity and hippocampal long-term potentiation. $J$ Neurosci 17: 4688-4699.

Mansbach RS, Geyer MA, Braff DL (1988). Dopaminergic stimulation disrupts sensorimotor gating in the rat. Psychopharmacology (Berl) 94: 507-514.

McCaughran Jr J, Mahjubi E, Decena E, Hitzemann R (1997). Genetics, haloperidol-induced catalepsy and haloperidol-induced changes in acoustic startle and prepulse inhibition. Psychopharmacology (Berl) 134: 131-139.

Meyer SE, Chrousos GP, Gold PW (2001). Major depression and the stress system: a life span perspective. Dev Psychopathol 13: 565-580.

Miller DD (2000). Review and management of clozapine side effects. J Clin Psychiatry 61(Suppl 8): 14-17.

Mitchell AJ (1998). The role of corticotropin releasing factor in depressive illness: a critical review. Neurosci Biobehav Rev 22: 635-651.

Moechars D, Lorent K, De Strooper B, Dewachter I, van Leuven F (1996). Expression in brain of amyloid precursor protein mutated in the alpha-secretase site causes disturbed behavior, neuronal degeneration and premature death in transgenic mice. EMBO J 15: 1265-1274.

Morris R, Grosveld F (1989). Expression of Thy-1 in the nervous system of the rat and mouse. Immunol Ser 45: $121-148$

Olivier B, Leahy C, Mullen T, Paylor R, Groppi VE, Sarnyai Z et al (2001). The DBA/2J strain and prepulse inhibition of startle: a model system to test antipsychotics? Psychopharmacology (Berl) 156: $284-290$

Ouagazzal AM, Jenck F, Moreau JL (2001). Drug-induced potentiation of prepulse inhibition of acoustic startle reflex in mice: a model for detecting antipsychotic activity? Psychopharmacology 156: 273-283.

Owens MJ, Nemeroff CB (1991). Physiology and pharmacology of corticotropin-releasing factor. Pharmacol Rev 43: 425-473.

Parham K, Willott JF (1988). Acoustic startle response in young and aging $\mathrm{C} 57 \mathrm{BL} / 6 \mathrm{~J}$ and $\mathrm{CBA} / \mathrm{J}$ mice. Behav Neurosci 102: 881-886.

Paylor R, Crawley JN (1997). Inbred strain differences in prepulse inhibition of the mouse startle response. Psychopharmacology 132: $169-180$.

Rigdon GC, Norman MH, Cooper BR, Howard JL, Boncek VM, Faison WL et al (1996). 1192U90 in animal tests that predict antipsychotic efficacy, anxiolysis, and extrapyramidal side effects. Neuropsychopharmacology 15: 231-242. 
Schatzberg AF, Posener JA, DeBattista C, Kalehzan BM, Rothschild AJ, Shear PK (2000). Neuropsychological deficits in psychotic versus nonpsychotic major depression and no mental illness. Am J Psychiatry 157: 1095-1100.

Schatzberg AF, Rothschild AJ (1992). Psychotic (delusional) major depression: should it be included as a distinct syndrome in DSM-IV? Am J Psychiatry 149: 733-745.

Swerdlow NR, Martinez ZA, Hanlon FM, Platten A, Farid M, Auerbach P et al (2000). Toward understanding the biology of a complex phenotype: rat strain and substrain differences in the sensorimotor gating-disruptive effects of dopamine agonists. $J$ Neurosci 20: 4325-4336.

Thompson RC, Seasholtz AF, Herbert E (1987). Rat corticotropinreleasing hormone gene: sequence and tissue-specific expression. Mol Endocrinol 1: 363-370.

Vasey MW, Thayer JF (1987). The continuing problem of false positives in repeated measures ANOVA in psychophysiology: a multivariate solution. Psychophysiology 24: 479-486.
Vidal M, Morris R, Grosveld F, Spanopoulou E (1990). Tissue-specific control elements of the Thy-1 gene. EMBO J 9: 833-840.

Wadenberg ML, Soliman A, VanderSpek SC, Kapur S (2001). Dopamine $\mathrm{D}_{2}$ receptor occupancy is a common mechanism underlying animal models of antipsychotics and their clinical effects. Neuropsychopharmacology 25: 633-641.

Wheeler Vega JA, Mortimer AM, Tyson PJ (2000). Somatic treatment of psychotic depression: review and recommendations for practice. J Clin Psychopharmacol 20: 504-519.

Wiessner C, Allegrini PR, Rupalla K, Sauer D, Oltersdorf T, McGregor AL et al (1999). Neuron-specific transgene expression of Bcl-XL but not Bcl-2 genes reduced lesion size after permanent middle cerebral artery occlusion in mice. Neurosci Lett 268: 119-122.

Willott JF, Carlson S, Chen H (1994). Prepulse inhibition of the startle response in mice: relationship to hearing loss and auditory system plasticity. Behav Neurosci 108: 703-713. 